\title{
Perancangan Iklan Layanan Masyarakat Tentang Bahaya Balap Liar Di Jalan Udayana
}

\author{
Rasta Maulana Rahmanto', Sandi Justitia Putra, M.A ${ }^{2}$, I Nyoman Miyarta Yasa M.I.Kom ${ }^{3}$ \\ ${ }^{1)}$ Program Studi Desain Komunikasi Visual Universitas Bumigora \\ Jln. Ismail Marzuki, Kota Mataram, Nusa Tenggara Barat. 83127, INDONESIA \\ ${ }^{1}$ rastamaulana1@gmail.com, ${ }^{2}$ Sandi.justita@ universitasbumigora.ac.id, \\ ${ }^{3}$ Miyarta.yasa@ universitasbumigora.ac.id
}

\begin{abstract}
ABSTRAK
Balap motor liar merupakan kegiatan yang bersifat negatif serta sarat akan bahaya baik terhadap diri mereka maupun orang lain. Kegiatan balap liar terjadi karena pergaulan yang negatif di kalangan para remaja dan kurangnya perhatian dari orang tua, keluarga maupun masyarakat lingkungan mereka. Untuk mengatasi agar tidak terjadi hal yang tidak diinginkan semakin parah diperlukan sosialisasi dan pengarahan kepada para remaja atau anak-anak muda, melalui berbagai macam cara atau dapat menggunakan berbagai macam media informasi, salah satunya adalah iklan layanan masyarakat. Tujuan perancangan iklan layanan masyarakat tentang bahaya balap liar adalah untuk meningkatkan kesadaran masyarakat untuk tertib berkendaraan di jalan raya, mengedukasi masyarakat Kota Mataram dan terciptanya suasana aman dan nyaman. Iklan Layanan Masyarakat yang akan dirancang menggunakan analisis dengan metode $5 \mathrm{~W}+1 \mathrm{H}$. Iklan layanan masyarakat yang penulis rancang ditujukan di wilayah kota Mataram khususnya di jalan Udayana dengan target audiens prioritas utama yaitu para remaja dan masyarakat umum. Rancangannya bertema tentang bahaya balap liar dengan menggunakan media cetak berupa baliho. Diharapkan dengan adanya Iklan Layanan Masyarakat melalui media baliho dapat memberikan kesadaran kepada pelaku aksi balap liar untuk tidak lagi melakukan kegiatan aksi balap liar, memberikan referensi kepada penelitian serupa untuk membuat rancangan yang benar-benar dapat mengena di hati target audience serta bagi pemerintah diharapkan mampu untuk mengambil tindakan yang lebih nyata dalam menangani bahaya balap motorliar.
\end{abstract}

Kata Kunci:Iklan Layanan Masyarakat, bahaya, Balap Liar

\begin{abstract}
Liar motor racing is a negative activity and is full of danger both to themselves and others. Liar racing activities occur because of negative relationships between teenagers and the attention of their parents, family or community environment. To overcome the unnecessary things that do not need to be more severe socialization and sacrifice is needed for teenagers or young children, through various ways to be able to use various kinds of information media, one of which is public service announcements. The purpose of designing public service announcements about the dangers of racers is to increase public awareness of orderly driving on the highway, educating the people of Mataram City and creating a safe and comfortable atmosphere. Public Service Announcements to be designed using the analysis method $5 \mathrm{~W}+1 \mathrm{H}$. Public service advertisements that writers have designed specifically in the city of Mataram specifically on Udayana Street with a primary target audience of teenagers and the general public. The design is themed about the dangers of liar racing by using printed media in the form of billboards. It is expected that the existence of Public Service Announcements through billboards can give awareness to racing racer supporters to no longer carry out racer racing activities, provide a reference for researchers who conduct research that can really hit the hearts of the target audience and for those who are expected to help to help take more real action in overcoming the dangers of motor racers.
\end{abstract}

Keywords: Public Service Advertisements, danger, Wild Race

\section{PENDAhUluan}

Pada zaman sekarang ini di era globalisasi, banyak sekali membawa dampak yang besar bagi kehidupan kelompok masyarakat maupun setiap individu, karena pada masa ini kita dengan mudah dapat mengakses berita-berita, musik, film dan gaya hidup masyarakat di negara lainmelalui internet. Percepatan danketerbukaan arus informasi inilah yang kemudian mengubah gaya hidup dan cara pandang seseorang termasuk di kalangan anak muda atau remaja. Apabila para remaja atau anak muda tidak dapat memilah 


\section{SASAK: DESAIN VISUAL DAN KOMUNIKASI}

Vol. 01 No. 2 (November) 2019, Hal 73-81, e-ISSN.2685-4120

https://journal.universitasbumigora.ac.id/index.php/sasak

hal-hal yang dapat membawa dampak positif dan dampak negatif, maka akan dapat menimbulkan berbagai macampermasalahan.

Anak-anak muda yang usianya masih remaja masih mencari jati dirinya dan ingin menunjukkan dan diakui kebolehan mereka oleh teman-temannya dan orang lain. Hormon adrenalin yang masih tinggi pada remaja tersebut membuat mereka ingin melakukan halhal yang menantang, salah satu contohnya adalah kegiatan balapan liar.

Kegiatan balap liar ini memiliki peminat yang sangat tinggi di Kota Mataram, terbukti dengan banyaknya titik- titik lokasi balap liar seperti di jalan lingkar utara,lingkar selatan, jalan udayana dan sebagainya.

Menurut Ketua Presidium Indonesia Police Watch (IPW) Neta S Pane, korban tewas dan luka-luka terus berjatuhan baik dari pembalap liar maupun masyarakat. Hal tersebut tentunya semakin meresahkan bagi masyarakat Kota Mataram sebab akibat dari balap liar yang tergolong sangat berbahaya tersebut dapat merenggut korban jiwa, baik dari pelaku aksi balap liar tersebut maupun dari pihak masyarakat umum sebagai pengguna jalan.

Dalam hal ini untuk mengatasi agar tidak terjadi hal yang tidak diinginkan semakin parah diperlukan sosialisasi dan pengarahan kepada para remaja atau anak-anak muda, melalui berbagai macam cara atau dapat menggunakan berbagai macam media informasi salah satunya iklan masyarakat.

Menurut

Susamto (1976:203)iklanlayanan masyarakat adalah suatu media informasi terkait setiap layanan masyarakat, penyebaran informasi yang tidak melalui pembelian ruang dan waktu, yang disiarkan mengenai pelayanan masyarakat dan dilaksanakan berdasarkan kegiatan non- profit (tidak mengejar keuntungan).

Dari permasalahan di atas, kegiatan balap liar di Kota Mataram masih sering dilakukan oleh para remaja dikarenakan beberapa faktor dan kurangnya edukasi kepada masyarakat.
Dalam hal untuk mengedukasi masyarakat khususnya para remaja di Kota Mataram tentang bahaya balap liar diperlukan sebuah usaha pemerintah dan aparat kepolisian, untuk memberi pengetahuan kepada masyarakat tentang dampak negatif atau bahaya yang bisa dialami jika melakukan aksi balap liar.

Dengan adanya iklan layanan masyarakat diharapkan dapat memberikan motivasi dan arahan untuk para remaja dan masyarakat di Kota Mataram agar bisa melakukan kegiatan yang lebih positif dan tidak ikut serta lagi dalam kegiatan balap liar.

\section{LANDASAN TEORI}

\section{- Ilustrasi}

Rohidi (1984:87) menjelaskan bahwa ilustrasi merupakan visualisasi dari sesuatu yang bertujuan untuk menerangkan ataupun memperindah sebuah naskah agar pembaca dapat merasakan pesan cerita yang ingin disampaikan.

Menurut Arifin dan Kusrianto (2009:7071), ilustrasi memiliki beberapa fungsi yaitu :

a) FungsiDeskriptif

Yaitu menggantikan sebuah penjelasan yang berupa teks yang bertujuan agarpembaca mudah memahami situasi atau keadaan yang digambarkan pada teks tersebut.

b) FungsiEkspresif

Yaitu sebagai visualisasi dari sebuah ide, konsep, ataupun gagasan yang masih berbentuk abstrak agar gagasan tersebut lebih mudahdipahami

c) FungsiAnalitis

Sebagai penggambaran dari sebuah sistem yang kompleks yang bertujuan agar mudah dipahami.

d) FungsiKualitatif

Yaitu sebagai visualisasi dari sebuah data

- Balap Motor Liar

Pengertian balap dalam Kamus Besar 


\section{SASAK: DESAIN VISUAL DAN KOMUNIKASI}

Vol. 01 No. 2 (November) 2019, Hal 73-81, e-ISSN.2685-4120

https://journal.universitasbumigora.ac.id/index.php/sasak

Bahasa Indonesia adalah adu kecepatan, dan pengertian liar adalah tidak teratur, tidak tertata. Secara umum pengertian balap motor liar adalah kegiatan adu kecepatan kendaraan bermotor yang dilakukan dengan tidak tertata, tidak berijin resmi dan dilakukan secara sembunyi-sembunyi dari aparat penegakhukum.

Balap motor liar merupakan kegiatan yang sangat beresiko dan membahayakan karena dilakukan tanpa standart keamanan yang memadai seperti penggunaan helm, jaket dan sarung tangan pelindung maupun kelengkapan sepeda motor seperti spions, lampu dan mesin yang tidak memadai. Selain itu, aksi kebutkebutan di jalan umum juga memicuterjadinya kemacetan sehingga dapat mengganggu kelancaran lalulintas disekitarnya. Tidak jarang juga balap motor liar menyebabkan terjadinya kecelakaan yang menimbulkan korban, baik korban luka maupun meninggal dunia.

Menurut Kartini Kartono, kebut- kebutan atau balap motor liar di jalanan yang mengganggu keamanan lalulintas dan membahayakan jiwa sendiri serta orang lain adalah salah satu wujud atau bentuk perilaku delinkuen atau nakal. Pada umumnya mereka tidak memiliki kesadaran sosial dan kesadaran moral. Tidak ada pembentukan ego dan super-ego, karena hidupnya didasarkan pada basis instinktif yang primitif. Mental dan kemauannya jadi lemah, hingga impuls-impuls, dorongan- dorongan dan emosinya tidak terkendali lagi seperti tingkah lakunya liar berlebih-lebihan. Tingkah laku yang dilakukan remaja tersebut dengan maksud mempertahankan harga dirinya dan untuk membeli status sosial untuk mendapatkan perhatian lebih dan penghargaan darilingkungan.

Faktor-faktor penyebab anak atau remaja melakukan balap motor liar yaitu faktor karena hobi, karena faktor taruhan (judi), faktor lingkungan, faktor keluarga dan faktor pengaruh teknologi. Selain itu ada faktor-faktor lain yang menjadipendorong terjadinya balap motor liar,yaitu:

a. Ketiadaan fasilitas sirkuit untuk balapan membuat pencinta otomotif ini memilih jalan raya umum sebagai gantinya, jikapun tersedia, biasanya harus melalui proses yangpanjang.

b. Gengsi dan nama besar, selain itu ternyata balap motor liar juga merupakan ajang adu gengsi dan pertaruhan namabesar.

c. Kemudian uang taruhan jugamenjadi faktor yang membuat balap motor liar menjadi suatuhobi.

d. Kesenangan dan memacu adrenalin. Bagi pelaku pembalap motor liar mengemukakan mereka mendapatkan kesenangan dari sensasi balap motor liar, ada rasa yang luar biasa yang tak dapat digambarkan ketika usai balapan

e. Keluarga dan lingkungan. Kurangnya perhatian orang tua, terjadi masalah dalam keluarga atau ketika terlalu berlebihannya perhatian orang tua kepada anak dan sebagainya juga dapat menjadi faktor pendorong anak melakukan aktivitas- aktivitas negatif seperti balap motor liar. Selain itu pengaruh atau ajakan teman juga dapat menjadifaktor.

- Iklan Layanan Masyarakat

Tinarbuko (2007) menjelaskan bahwa tampilan ILM harus tepat sasaran yang dituju karena pada dasarnya ILM bertujuan untuk menggugah kesadaran masyarakat akan pemecahan suatu masalah sosial yang sedang aktual. ILM merupakan aktivitas periklanan sosial yang berlandaskan gerakan moral, mengemban tugas mulia membangun masyarakat melalui pesan- pesan sosial yang dikemas secara kreatif. Mengkaji ILM dalam seni visual tidak lepas dari unsur peranan desain komunikasivisual. 
SASAK: DESAIN VISUAL DAN KOMUNIKASI

Vol. 01 No. 2 (November) 2019, Hal 73-81, e-ISSN.2685-4120

https://journal.universitasbumigora.ac.id/index.php/sasak

Dalam menentukan strategi ILM, pengiklan harus terlebih dahulu menentukan segmentasi atau target audience di suatu

lingkungan masyarakat. Merujuk pada pandangan Kasali (1998) ada tiga jenis pengelompokkan segmentasi masyarakat yang digunakan dalam mencapai tujuan, yaitu:

1. Demografis. Segmentasi ini membagi masyarakat berdasarkan karakteristik demografinya seperti usia, pendidikan, gender, pendidikan, pekerjaan, dan sebagainya.

2. Geografis. Segmentasi ini membagi- bagi segmentasi masyarakar berdasarkan jangkauan geografisnya. Setiap wilayah memiliki karakter yang berbeda dengan wilayahlainnya.

3. Psikografis. Segmentasi ini membagi masyarakat berdasarkan perilaku, gaya hidup dan kepribadian seseorang. Gaya hidup merupakan cerminanseseorang

- $\quad$ KenakalanRemaja

Kartono (ilmuwan sosiologi) menjelaskan Kenakalan Remaja atau dalam bahasa Inggris dikenal dengan istilah juvenile delinquency merupakan gejala patologis sosial pada remaja yang disebabkan oleh satu bentuk pengabaian sosial. Akibatnya, mereka mengembangkan bentuk perilaku yangmenyimpang.

Menurut Santrock (2007:571) "Kenakalan remaja merupakan kumpulan dari berbagai perilaku remaja yang tidak dapat diterima secara sosial hingga terjadi tindakan kriminal".

Mussen, dkk (1994) Mendefinisikan kenakalan remaja sebagai perilaku yang melanggar hukum atau kejahatan yang biasanya dilakukan oleh anak remaja yang berusia 16-18 tahun, jika perbuatan ini dilakukan oleh orang dewasa maka akan mendapat sangsi hukum.

Hurlock (1973) Menyatakan kenakalan remaja adalah tindakan pelanggaran hukum yang dilakukan oleh remaja, dimana tindakan tersebut dapat membuat individu yang melakukannya masukpenjara

\section{METODE PENELITIAN}

\section{Metode Perncangan}

Dalam penelitian ini menggunakan metode Design Thinking yang merupakan metode penyelesaian masalah yang berfokus ke pada pengguna. Adapun beberapa metode tersebut yaitu, Empathize, Define, Ideate, Prototype, Test.

\section{Metode Analisisa Data}

Dalam analisis ini penulis menggunakan metode $5 \mathrm{~W}+1 \mathrm{H}$ untuk pengumpulan data yang diperlukan untuk merancang karya

-What?

Karya iklan layanan masyarakat yang akan dirancang penulis menggunakanbaliho

-When?

Karya iklan layanan masyarakat ini diterapkan setiap satu kali dalam satu tahun pada awal bulan januari.

-Where?

Penerapan karya iklan layananmasyarakat ini akan diterapkan pada jalan Udayana KotaMataram

-Who?

Target audiens iklan layanan masyarakat ini 12 tahun sampai 20 tahun

-Why?

Karya iklan ini dibuat karena masih kurangnya kesadaran para remaja dalam menggunakan jalan raya dengan bijak dan juga masih kurangnya edukasi kepada para remaja mengenai balap liar 
-How?

Karya iklan layanan masyarakat ini diterapkan pada jalan Udayana. Karya iklan layanan masyarakat ini menggunakan media baliho berisi ilustrasi dan untuk menarik perhatian audiens yang melewati jalan tersebut.

\section{VISUALISASI}

- MomenVisual

Dalam merancang sebuah ilustrasi tentang bahaya balap liar penulis menggunakan ilustrasi yang menarik perhatian audiens dengan visual yang simple namun mudah dipahami

- CitraVisual

Citra visual yang ingin ditonjolkan dalam ilustrasi ini adalah ilustrasi balap liar itu sendiri sebagai kegiatan yang negatif dan berbahaya. Dengan merancang iklan layanan masyarakat tentang bahaya balap liar ini diharapkan biasa menjadi mediapembelajaran atau edukasi untuk para remaja dan masyarakat KotaMataram.

- TipeTipografi

Untuk pemilihan jenis font sangat berpengaruh untuk menyampaikan isi pesan karena font menjadi bagian penting dalam sebuah isi pesan yang terkandung didalamnya. Untuk menciptakan iklan layanan masyarakat yang terkesan tegas, penulis memilih jenis font sans serif yang dimana jenis font ini adalah jenis font tidak memiliki kaki yang sifatnya tegas dan jelas untuk dilihat. Bentuk font yang ingin penulis gunakan harus memvisualkan kesan tegas sesuai dengan tema yang akan diangkat. Berikut beberapa pilihan jenis font yang akan digunakanpenulis:

1. Keep calmmed

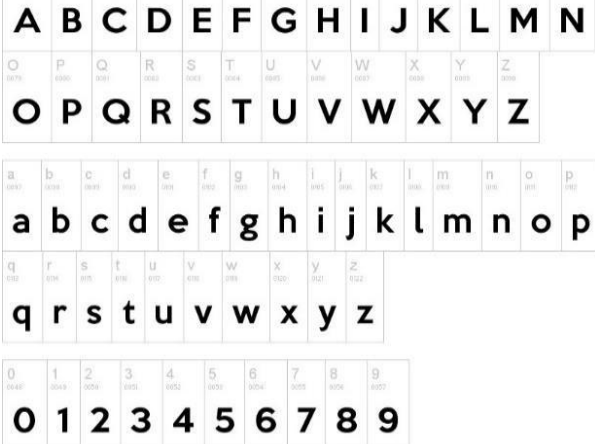

Gambar 1.Jenis font tipografi keep calm med

Jenis font diatas ini nantinya akan digunakan pada kalimat slogan dan sclosing

2. Bebasneue

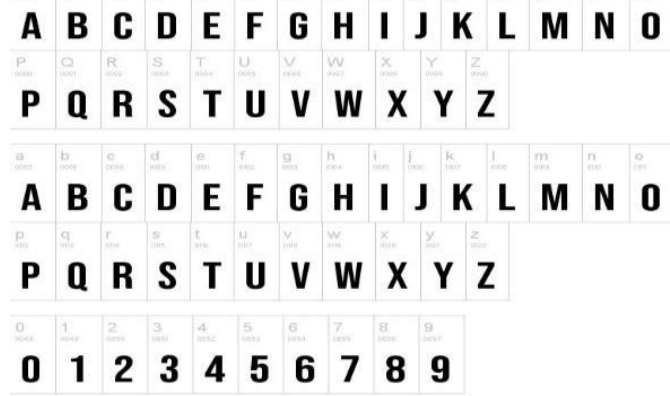

Gambar 2.Jenis font tipografi Bebas neue

Jenis font diatas ini nantinyaakan digunakan untukjudul

- ToneWarna

Dalam merancangan iklan layanan masyarakat ini penulis menggunakan warnawarna yang cerah sebagai daya tarik untuk masyarakat terutama para remaja Dibawah ini adalah pilihan warna-warna yang menjadi acuan referensi penulis.

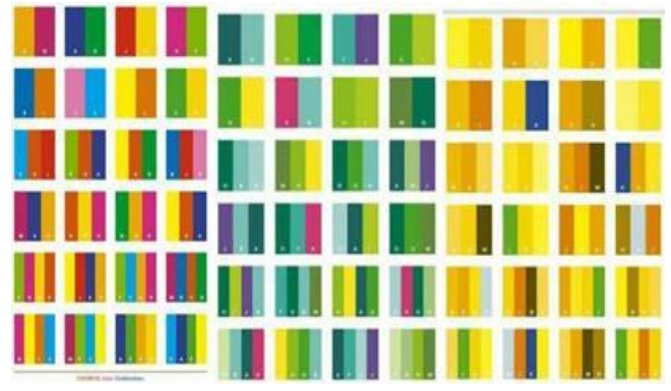

Gambar 3.Acuan JenisWarna 


\section{SASAK: DESAIN VISUAL DAN KOMUNIKASI}

Vol. 01 No. 2 (November) 2019, Hal 73-81, e-ISSN.2685-4120

https://journal.universitasbumigora.ac.id/index.php/sasak

Axial Layout tata letak yang memiliki tampilan visual yang kuat di tengah halaman dengan tampilan element pendukung di sekeliling gambar utama biasanya berupa gambar atau tulisan yang berhubungan dengan tampilan di tengah halaman sebagai titik pusatnya.

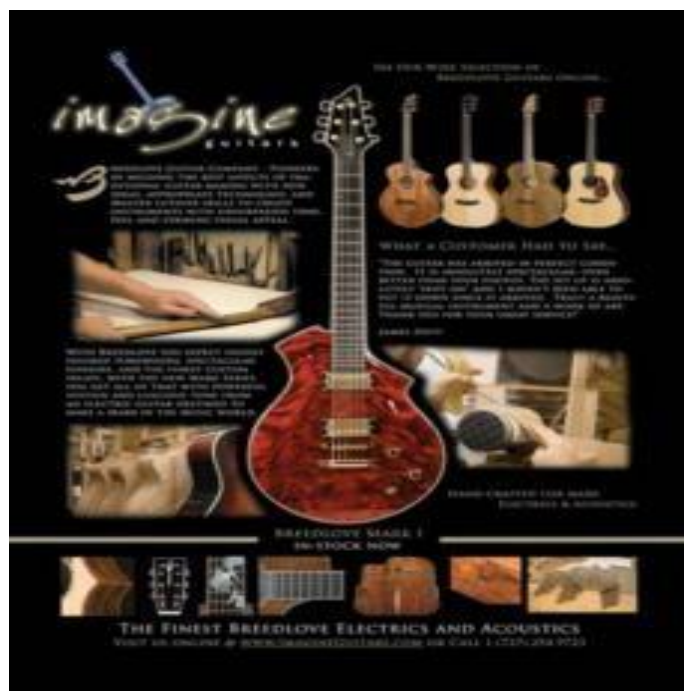

Gambar 4.Axial Layout 1

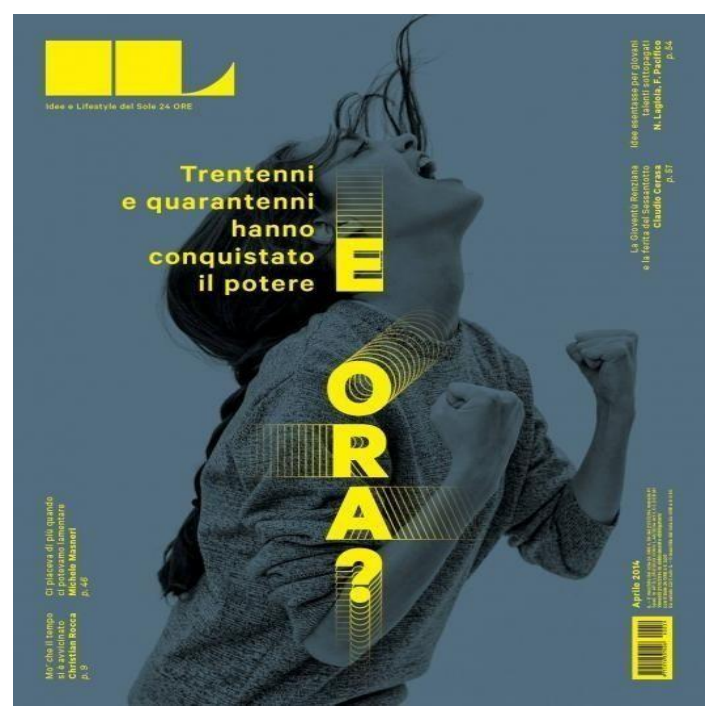

Gambar 5.Axial Layout 2

- GayaDeain

Gaya Flat Design Style merupakan gaya desain yang akan digunakan pada perancangan iklan layanan masyarakat ini akan lebih dominan ke ilustrasi

- GayaVisual

Gaya visual yang digunakan yaitu bisa dimengerti sederhana dan jelas agar mereka yang tadinya tidak mengerti akanmenjadimengerti. Sehingga kesalah pahaman dalamkomunikasi visual tidak akan terjadi

- ModelIlustrasi

Model ilustrasi yang akan dibuat berupa ilustrasi vektor menyediakan banyak informasi berguna dengan cara yang mudah dimengerti oleh pengendara yang melewati jalan Udayana.

\section{Desain Media Utama (Baliho)}

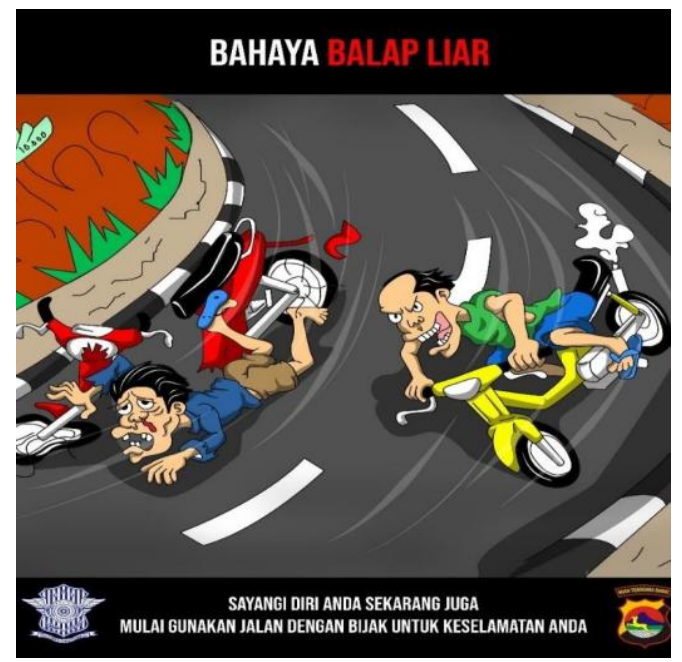

Gambar 6.Gambar Karya Baliho 1

Gambar di atas merupakan rancangan baliho yang telah dibuat kemudian akan diterapkan pada karya baliho yang lokasi penerapannya berada di jalan Udayana berdekatan dengan kantor Badan Pengawas Pemilihan Umum. Gaya desain yang ingin ditonjolkan dalam perancangan baliho ini adalah flat desainyang simpel yang memiliki tampilan visual yang kuat di tengah (Axial Layout).Pada desain ilustrasi ini penulis menceritakan remaja yang mengendarai sepeda motor melaju dengan kecepatan tinggi 


\section{SASAK: DESAIN VISUAL DAN KOMUNIKASI}

Vol. 01 No. 2 (November) 2019, Hal 73-81, e-ISSN.2685-4120

https://journal.universitasbumigora.ac.id/index.php/sasak

mengejar garis finis dan salah satu dari remaja tersebut terjatuh hingga mengakibatkan luka-luka. Kesan yang ingin disampaikan pada ilustrasi ini agar target audiens tidak terlibat atau

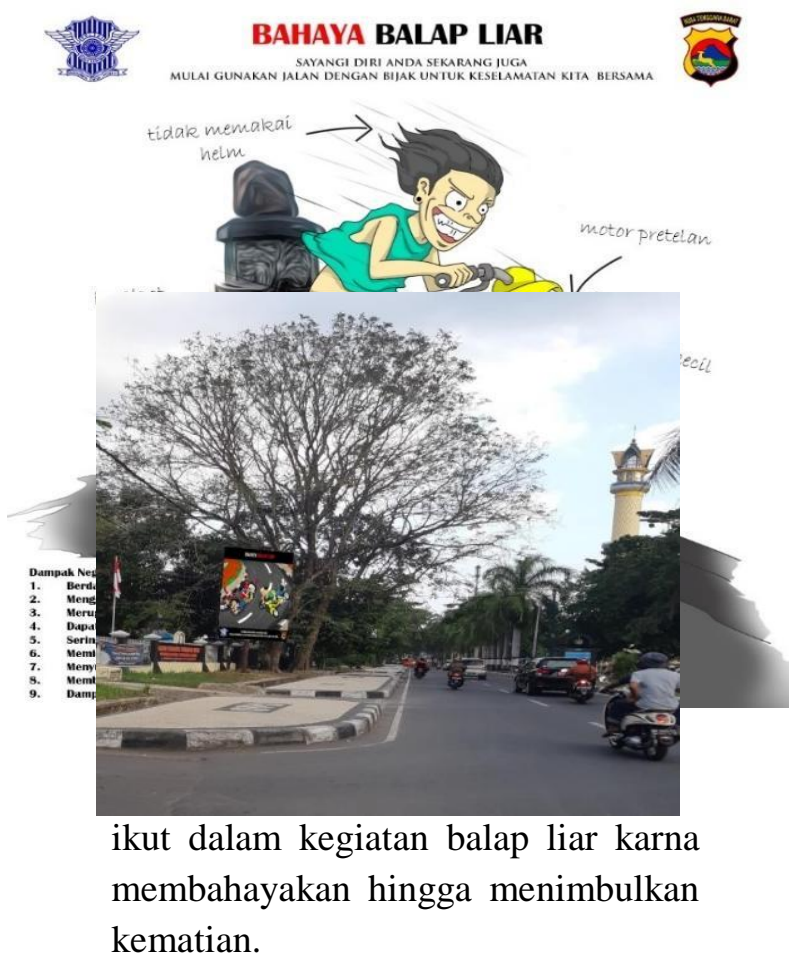

\section{Desain Media Pendukung (Poster)}

Gambar 7.Gambar Karya Pendukung Poster
Sedangkan untuk media pendukungnya menjelaskan informasi lebih mendetail tentang ilustrasi balap liar yang berada di jalan Udayana dengan monumen bumigora berbentuk batu yang menjadi ciri khas dari tempat tersebut

\section{Hasil MockUp Media Utama (Baliho) \\ Gambar 8. lokasi Karya baliho}

Gambar di atas merupakan tempat penerapan karya utama yang berada di jalan Udayana tepat berada didepan kantor Badan Pengawas PemilihanUmum.

\section{Hasil Mockup Media Pendukung}

Pada tahap ini merupakan tahap dimana suatu karya yang menjadi media utama harus dapat di dukung oleh media pendukung yang bertujuan untuk menggiring target audience yang dituju untuk dapat menjangkau karya utama. Dan media pendukung dapat menjadi media pengenalan serta pengingat bagi target audience. Media pendukung yang penulis gunakan berupa poster berisi informasi yang lebih mendetail mengenai dampak negatif balapliar.

Lokasi penempatan poster untuk mendukung media utama ada diberbagai titik antara lain yaitu: 


\section{SASAK: DESAIN VISUAL DAN KOMUNIKASI}

Vol. 01 No. 2 (November) 2019, Hal 73-81, e-ISSN.2685-4120

https://journal.universitasbumigora.ac.id/index.php/sasak

- Jalan GiliTrawangan

Gambar 9.Lokasi pemasangan mockup 1

- JalanMahoni

Gambar 10.Lokasi pemasangan mockup 2

- JalanAneka

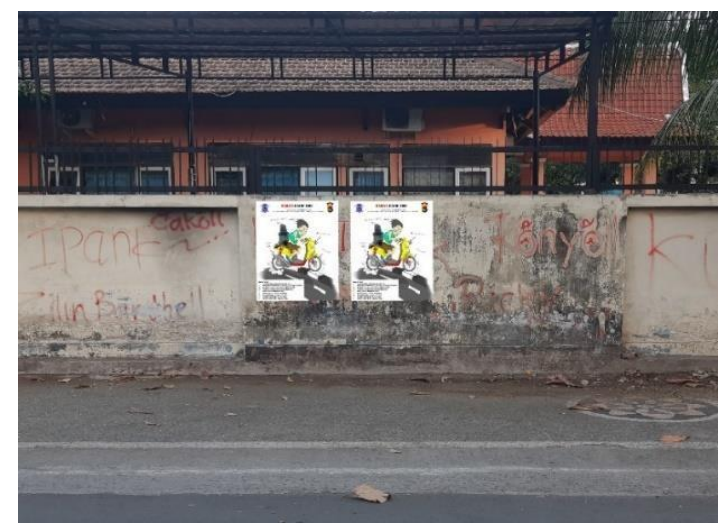

Gambar 11.Lokasi pemasangan mockup 3

- JalanPuring

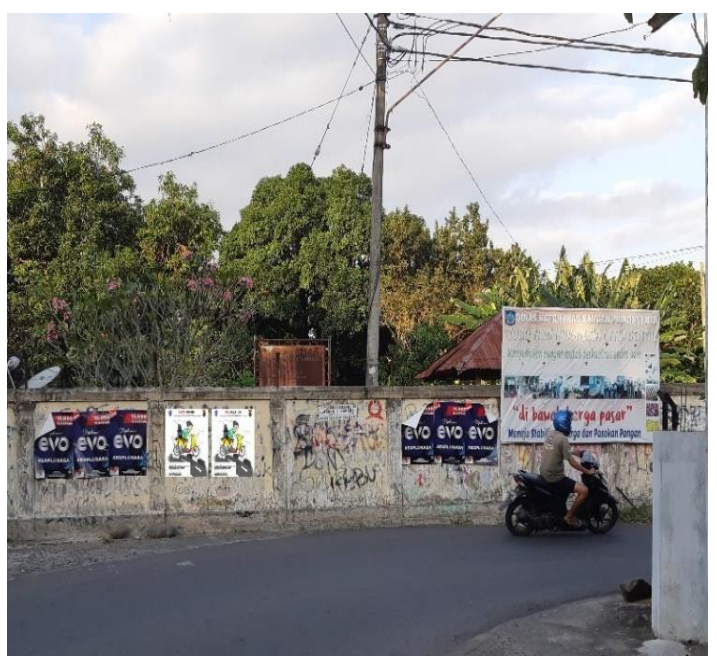

Gambar 12.Lokasi pemasangan mockup 4

\section{KESIMPULAN}

Balap motor liar merupakan kegiatan beradu cepat kendaraan motor yang dilakukan di jalan raya dan anpa disertai dengan izin. Balap motor liar merpakan kegiatan yang bersifat negatif serta sarat akan bahaya baik terhadap diri mereka maupu orang lain. Kegiatan balap liar terjadi karen pergaulanyang negatif di kalangan para remaja dan kurangnya perhatian dari orang tua, keluarga maupun masyarakat lingkungan mereka.

Untuk mengurangi kegiatan balap liar, dapat dilakukan dengan berbagai cara seperti pembuatan iklan layanan masyarakat, iklan

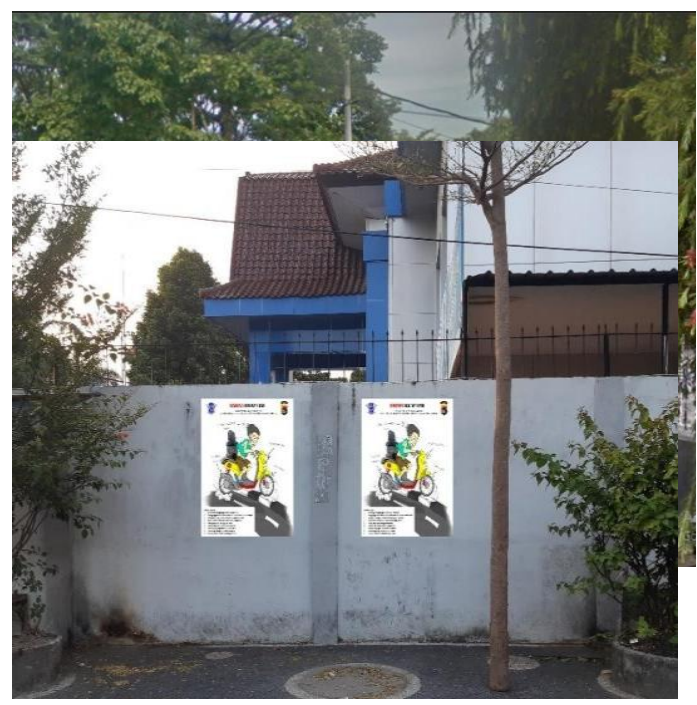

layanan masyarakat merupakan iklan sosial yang bertujuan kepentingan layanan masyarakat, berupa suatu himbauan, memberikan informasi/ ajakan tingkah laku tertentu dengan harapan munculnya tambahan pengetahuan, kesadaran sikap dan perubahan perilaku. Iklan layanan masyarakat pada perancangan ini memberikan edukasi dan kesan khawatir / takut bagi pelaku balap liar. Iklan layanan masyarakat yang penulis rancang ditujukan di wilayah kota Mataram khususnya di jalan Udayana. Rancangannya bertema tentang bahaya balap liar dengan menggunakan media cetak berupa baliho..

\section{REFERENSI}

[1] Aroma, I. S., \& Suminar, D. R. (2012). Hubungan antara tingkat kontrol diri dengan kecenderungan perilaku kenakalan remaja. Jurnal Psikologi Pendidikan dan Perkembangan, 1(2), 1-6.

[2] Canagara, Hafied. 2006. Pengantar Ilmu Komunikasi.Jakarta: PT Raja Grafindo Persada

[3] Daryanto. 1993. Media Visual Pengajaran Teknik.Tarsito: Bandung.

[4] Erdalina, W., \& Evanita, S. (2015). Pengaruh Kualitas Produk, Harga Dan Iklan Televisi Terhadap Keputusan Pembelian Produk Kosmetik Merek Citra Hand And Body Lotion Di Pariaman. Jurnal 
SASAK: DESAIN VISUAL DAN KOMUNIKASI

Vol. 01 No. 2 (November) 2019, Hal 73-81, e-ISSN.2685-4120

https://journal.universitasbumigora.ac.id/index.php/sasak

Riset Manajemen Bisnis dan Publik, 3(1).

[5] Jefkins, Frank. 1997. Periklanan. Jakarta: Erlangga.

[6] Kasali, Rhenald. 1992. Manajemen Periklanan Konsep Dan Aplikasinya Di Indonesia. Jakarta: Pustaka Utama Grafiti.

[7] Kasiram, Moh. 2008. Metodologi Penelitian Kualitatif dan Kuantitatif. Malang : UIN-Malang Pers.

[8] Kriyantono 2008. Teknik Praktis Kiat Komunikasi.Jakarta:Kencana Prenada Media Group.

[9] Kurniasih. (2014). Peranan Desain Komunikasi Visual Dalam Perancangan Buku. 285-290.

[10] Lee Monle dan Carla Johnson. 2004.Prinsip-Prinsip Pokok Periklanan Dalam Perspektif Global.

[11] Meleong J.Lexy. 2005. Metodologi Penelitian Kualitatif. Bandung:

[12] Nisa, Naima Khoiru. 2015. Strategi Kreatif Iklan Layanan Masyarakat (ILM) dalam Pemasaran Sosial. Dalam Jurnal Ilmu Komunikasi. Vol. 4. No.2Remaja Rosdakarya.

[13] Rosanti Amalia. Fokky Fuad.2015. Budaya Hukum Balap Liar Di Ibukota. Vol. 12. No. 1

[14]Runtiko Agus Ganjar. 2013. Desain Iklan Layanan Masyarakat Pemerintah. Dalam Penelitian Komunikasi Vol. 16. No. 1

[15] Rustan, S. (2009). LAYOUT dasar dan penerapannya.Jakarta: PT. Gramedia Pustaka Utama.

[16] Santoso, Hari. 2015. Upaya Meningkatkan Minat dan Budaya Membaca Buku Melalui Iklan Layanan Masyarakat. Pada Perpustakaan Universitas Negeri Malang

[17] Wardhani, Rayenda Puti.
"PERANCANGAN

BUKU INTERAKTIF MENGENAI MIOPI UNTUK ANAK." 